\title{
Composição florística do componente arbóreo e afinidade fitogeográfica de uma floresta semidecídua em Nova Lima, MG
}

\author{
MÁRCIO DE SOUZA WERNECK ${ }^{1,4}$, SAULO GARCIA REZENDE², ANA ELISA BRINA² e \\ EDIVANI VILLARON FRANCESCHINELLI ${ }^{3}$
}

(recebido: 11 de agosto de 2008; aceito: 16 de setembro de 2010)

\begin{abstract}
Floristic composition of tree species and phytogeographic affinity of a semideciduous forest in Nova Lima, Minas Gerais State, Brazil). The Nova Lima city (metropolitan area of Belo Horizonte, Minas Gerais State, Brazil) is located in an ecotone between Cerrado (Brazilian Savanna) and Atlantic Forest, wich are two of the world's biodiversity hotspots. A floristic survey was carried out in a semideciduous forest $\left(20^{\circ} 00^{\prime} \mathrm{S}\right.$ and $\left.43^{\circ} 55^{\prime} \mathrm{W}\right)$ in order to establish its relations with other forests (rain forest and semideciduous) from both hotspots, as well as to assess their phytogeographical insertion. The region is under high pressure due to urban expansion. The floristic survey of the semideciduous forest was based on specimens of woody plants collected both in and outside of 44 plots of $20 \times 5$ meters. The studied forest was compared with other 72 forests of Minas Gerais, São Paulo, Espírito Santo, Rio de Janeiro and Goiás States and the Federal District using multivariate analyses. At semideciduous forest 205 species of 49 botanical families were found. The record of species with restricted distribution to Atlantic Forest was 15 times greater than in the Cerrado. The tree flora of the semideciduous forest studied is a subset of that of rainforests, with species that are more efficient in coping with a longer dry season. Thus, the forest may be considered an Atlantic Forest.
\end{abstract}

Key words - atlantic forest, cerrado, floristic, phytogeography, semideciduous forests

RESUMO - (Composição florística do componente arbóreo e afinidade fitogeográfica de uma floresta semidecídua em Nova Lima, MG). O Município de Nova Lima, na Região Metropolitana de Belo Horizonte (MG), encontra-se no contato entre os domínios do Cerrado e da Mata Atlântica, que são dois hotspots de biodiversidade. Uma amostragem florística foi realizada em uma floresta semidecídua $\left(20^{\circ} 00^{\prime} \mathrm{S}\right.$ e $\left.43^{\circ} 55^{\prime} \mathrm{W}\right)$ com o objetivo de avaliar sua relação com outras florestas semidecíduas e ombrófilas presentes em ambos os domínios a avaliar sua afinidade fitogeográfica. A região estudada encontra-se sob alta pressão antrópica devido à expansão urbana. A amostragem florística foi baseada na coleta de todos os indivíduos lenhosos presentes fora e dentro de 44 parcelas retangulares de $20 \times 5$ metros. A floresta estudada foi comparada com outras presentes no Distrito Federal e dos Estados de Minas Gerais, São Paulo, Espírito Santo, Rio de Janeiro e Goiás usando análises multivariadas. Foram encontradas 205 espécies representando 49 famílias botânicas. O registro de espécies com distribuição restritas a Mata Atlântica foi 15 vezes maior que do Cerrado. A flora arbórea da floresta estudada é, em boa medida, um subconjunto da flora das florestas ombrófilas, tendo espécies provavelmente mais eficientes em resistir e competir sob condições de seca mais prolongada. Assim, a floresta semidecídua estudada pode ser considerada como floresta atlântica sensu lato.

Palavras-chave - cerrado, fitogeografia, florestas semidecíduas, florística, mata atlântica

\section{Introdução}

Afloresta estacional semidecídua é a fitofisionomia que se localiza tanto na porção interior do domínio da Mata Atlântica quanto nos interflúvios com o domínio do Cerrado (IBGE 2004), apresentando uma flora arbórea mais bem estudada, se comparada com

1. Universidade Federal do ABC, Centro de Ciências Naturais e Humanas, Av. dos Estados, 5001, 09210-971 Santo André, SP, Brasil.

2. Sete Soluções e Tecnologia Ambiental Ltda., Av. Getúlio Vargas, 1420/16o andar, 30112-021 Belo Horizonte, MG, Brasil.

3. Universidade Federal de Goiás, Departamento de Biologia Geral, Caixa Postal 131, 74001-970 Goiânia, GO, Brasil.

4. Autor para correspondência: marcio.werneck@ufabc.edu.br a floresta ombrófila densa (Leitão-Filho 1993). De uma forma geral, as florestas semidecíduas situadas na Mata Atlântica recebem influência florística da floresta ombrófila densa, enquanto que as localizadas no Cerrado recebem influência deste domínio (Silva 2000). No Estado de Minas Gerais, as florestas semidecíduas situam-se principalmente na região centro-sul e leste (IBGE 2004) e encontram-se, em geral, reduzidas a fragmentos esparsos, pois foi a tipologia mais rápida e extensamente devastada no estado desde o período colonial (Oliveira-Filho \& Machado 1993).

A Região Metropolitana de Belo Horizonte (MG) localiza-se na zona de contato entre os domínios do Cerrado e da Mata Atlântica (IBGE 2004), cuja 
vegetação original era composta por um mosaico onde predominavam formações típicas do Cerrado em encostas suaves e topos de morros, mescladas a florestas semidecíduas nas encostas próximas a fundos de vales adjacentes a cursos d'água. Assim, é de se esperar que as florestas semidecíduas presentes na Região Metropolitana de Belo Horizonte devam apresentar uma influência tanto da floresta ombrófila densa (característica do domínio da Mata Atlântica) quanto do domínio Cerrado. Entretanto, não há, até o presente momento, estudos que corroborem essa afirmativa. Embora a vegetação original esteja em grande parte suprimida pelo crescimento desordenado das cidades, ainda podem ser encontrados fragmentos de floresta semidecídua em bom estado de conservação na Região Metropolitana de Belo Horizonte, em locais de interesse minerário, de difícil acesso ou protegidos sob a forma de Unidades de Conservação.

O presente estudo objetiva realizar o levantamento florístico das espécies arbóreas de uma floresta semidecídua no município de Nova Lima (MG), Região Metropolitana de Belo Horizonte, e investigar a sua relação com outras florestas semidecíduas e ombrófilas densas do domínio da Mata Atlântica, presentes na região Sudeste, e com florestas semidecíduas do domínio do Cerrado, ocorrentes no Distrito Federal e nos estados de Goiás, Minas Gerais e São Paulo. Em função da controvérsia de se considerar a floresta semidecídua como extensão interiorana da Mata Atlântica, este trabalho torna-se importante devido à área estudada estar localizada na zona de contato entre os domínios da Mata Atlântica e do Cerrado. Dessa forma, o presente trabalho contribuirá para definir a posição fitogeográfica da floresta estudada, gerando subsídios para que estratégias conservacionistas na área de estudo sejam mais bem elaboradas, uma vez que a região de estudo sofre uma grande pressão para expansão imobiliária.

\section{Material e métodos}

Localizada no Município de Nova Lima, Região metropolitana de Belo Horizonte, a área estudada apresenta-se como uma floresta semidecídua recobrindo o fundo de vale e encosta adjacente onde o solo é mais profundo, ao longo do Ribeirão Cristais (19 $59^{\prime} 30^{\prime \prime}$ a $20^{\circ} 00^{\prime} 30^{\prime \prime} \mathrm{S}$ e $43^{\circ} 54^{\prime} 30^{\prime \prime}$ a $43^{\circ} 55^{\prime} 30^{\prime \prime} \mathrm{W}$ ), na porção sul da Cadeia do Espinhaço. A região é conhecida como Vale dos Cristais e possui um clima do tipo Cwb de Köppen (1948) subtropical de altitude, tendo verões amenos e estiagem de inverno. Apresenta uma temperatura média anual de
$22,6{ }^{\circ} \mathrm{C}$ e uma precipitação média anual de $1.670 \mathrm{~mm}$. As altitudes variam de $960 \mathrm{~m}$ a $1.180 \mathrm{~m}$, predominando solos dos tipos Cambissolos e Neossolos (Cetec 1983), tendo raros trechos de elevada declividade com afloramentos da rocha de origem.

Os dados foram coletados por meio de um estudo fitossociológico com a aplicação de 44 parcelas de $100 \mathrm{~m}^{2}(20 \times 5 \mathrm{~m})$ e um levantamento florístico ao longo de toda a floresta presente na área de estudo. No caso do estudo fitossociológico, as parcelas foram alocadas perpendicularmente ao curso do Ribeirão Cristais nas áreas de melhor acesso, em função da elevada declividade em vários trechos. A amostragem fitossociológica consistiu na inclusão de todos os indivíduos com DAP (diâmetro do caule ao nível do peito, ou 1,3 $\mathrm{m}$ de altura do solo) igual ou superior a $5 \mathrm{~cm}$. O levantamento florístico foi efetuado entre janeiro/2002 a julho/2004, por meio de um caminhamento arbitrário de varredura e o estudo fitossociológico de janeiro a abril de 2002.

O material botânico foi coletado com auxílio de tesoura de poda alta e determinado por exame de especialistas, comparação com a coleção do herbário do Departamento de Botânica da Universidade Federal de Minas Gerais (BHCB) e com o auxílio da literatura apropriada. O material testemunho fértil encontra-se depositado no herbário BHCB. A listagem do material registrado foi elaborada segundo o sistema de classificação do Angiosperm Phylogeny Group (APG II 2003), sendo apresentada em ordem alfabética por famílias, gêneros e espécies.

A listagem da flora arbórea da floresta semidecídua presente no Vale dos Cristais foi comparada com outras 72 listagens produzidas em áreas de florestas semidecíduas e ombrófilas densas presentes no Distrito Federal, Goiás, Minas Gerais, São Paulo, Rio de Janeiro e Espírito Santo (tabela 1), englobando, assim, trechos florestais dos domínios da Mata Atlântica e do Cerrado. Todas essas florestas foram classificadas conforme a terminologia de Veloso et al. (1991), por considerar critérios não só da fisionomia da vegetação, mas também das condições ambientais prevalentes. Os limites altitudinais das 73 florestas compiladas (incluindo o presente estudo) seguiram os limites estabelecidos por Oliveira-Filho et al (1994). A definição do domínio que pertence cada uma das 73 florestas apresentadas na tabela 1 baseou-se nas informações presentes em IBGE (2004). As áreas de tensão ecológica entre os domínios (sensu IBGE 2004) e os encraves de Cerrado, na Mata Atlântica, foram considerados com as áreas de transição entre os domínios.

As 73 listagens de espécies foram convertidas em uma matriz de dados binários (presença/ausência) que passou por uma revisão para a averiguação de sinonímias dos epítetos, contendo, por fim, uma matriz binária com 2.181 espécies. Posteriormente, as espécies representadas em menos que cinco áreas na amostragem total foram eliminadas, pois influenciam muito pouco os resultados das análises multivariadas e aumentam, sem necessidade, o volume dos cálculos (Krebs 
Tabela 1. Localização, fitofisionomia, domínio fitogeográfico, tipo climático (Köppen 1948) e referência dos 73 levantamentos florísticos de florestas na Região Sudeste do Brasil, Goiás e Distrito Federal, incluindo presente trabalho. (FES = floresta estacional semidecidual; $\mathrm{FOD}$ = floresta ombrófila densa; $\mathrm{MA}=$ Mata Atlântica; $\mathrm{Ce}=\mathrm{Cerrado} ; \mathrm{MA} / \mathrm{Ce}=$ transição ou encraves entre os domínios da Mata Atlântica e do Cerrado).

Table 1. Location, phytophysiognomy, phytogeographic dominium, climatic type (Köppen 1948) and citation for each of the 73 forests in Southeast Brazil, Goiás State and Federal District, including the studied forest. (FES = seasonal semideciduous forests; $\mathrm{FOD}=$ atlantic rain forest; $\mathrm{MA}=$ Atlantic Forest $\mathrm{Ce}=\mathrm{Cerrado} ; \mathrm{MA} / \mathrm{Ce}=$ ecotone or enclaves between Atlantic Forest and Cerrado).

\begin{tabular}{|c|c|c|c|c|c|}
\hline Código & Localização & Tipologia & Domínio & Clima & Fonte \\
\hline Vcr * & Vale dos Cristais, Nova Lima - MG & FES montana & $\mathrm{MA} / \mathrm{Ce}$ & $\mathrm{Cw}$ & Presente trabalho \\
\hline Ara & Araguari-MG & FES montana & $\mathrm{Ce}$ & Aw & Oliveira-Filho \& Fontes (2000) \\
\hline Bar* & APE Barreiro, Belo Horizonte - MG & FES montana & $\mathrm{MA} / \mathrm{Ce}$ & $\mathrm{Cw}$ & Meyer et al. (2004) \\
\hline Bet & Betim - MG & FES montana & $\mathrm{MA} / \mathrm{Ce}$ & $\mathrm{Cw}$ & Oliveira-Filho \& Fontes (2000) \\
\hline Boc * & Bocaiúva-MG & FES montana & $\mathrm{Ce}$ & Aw & Oliveira-Filho \& Fontes (2000) \\
\hline $\mathrm{Bsu} *$ & Bom Sucesso - MG & FES montana & MA & $\mathrm{Cw}$ & Oliveira-Filho \& Fontes (2000) \\
\hline Car* & Carrancas - MG & FES altomontana & $\mathrm{MA} / \mathrm{Ce}$ & $\mathrm{Cw}$ & Oliveira-Filho et al. (2004) \\
\hline $\mathrm{Cmd} *$ & Camanducaia - MG & FOD altomontana & MA & $\mathrm{Cw}$ & França e Stehmann (2004) \\
\hline Cng & Carangola $-\mathrm{MG}$ & FES submontana & MA & $\mathrm{Cw}$ & Oliveira-Filho \& Fontes (2000) \\
\hline Con & Congonhas - MG & FES altomontana & MA & $\mathrm{Cw}$ & Oliveira-Filho \& Fontes (2000) \\
\hline Cqt $*$ & Conquista $-\mathrm{MG}$ & FES submontana & $\mathrm{MA} / \mathrm{Ce}$ & Aw & Oliveira-Filho \& Fontes (2000) \\
\hline Crt & Caratinga $-\mathrm{MG}$ & FES submontana & MA & $\mathrm{Cw}$ & Oliveira-Filho \& Fontes (2000) \\
\hline Ibi & Ibituruna $-\mathrm{MG}$ & FES montana & MA & $\mathrm{Cw}$ & Silva et al. (2003) \\
\hline Ibt & Ibitipoca - MG & FOD altomontana & MA & $\mathrm{Cw}$ & Carvalho et al. (2000) \\
\hline Imd & Itambé do Mato Dentro - MG & FES submontana & $\mathrm{MA} / \mathrm{Ce}$ & $\mathrm{Cw}$ & Oliveira-Filho \& Fontes (2000) \\
\hline Ing * & Ingaí - MG & FES montana & $\mathrm{MA} / \mathrm{Ce}$ & $\mathrm{Cw}$ & Botrel et al. (2002) \\
\hline Itu * & Itutinga $-\mathrm{MG}$ & FES montana & $\mathrm{MA} / \mathrm{Ce}$ & $\mathrm{Cw}$ & Oliveira-Filho \& Fontes (2000) \\
\hline Jui & Juiz de Fora - MG & FOD montana & MA & $\mathrm{Cw}$ & Oliveira-Filho \& Fontes (2000) \\
\hline $\mathrm{Lav} *$ & RB Poço Bonito, Lavras - MG & FES montana & $\mathrm{MA} / \mathrm{Ce}$ & $\mathrm{Cw}$ & Oliveira-Filho \& Fontes (2000) \\
\hline $\mathrm{Ldu}$ & Lima Duarte - MG & FOD montana & MA & $\mathrm{Cw}$ & Oliveira-Filho \& Fontes (2000) \\
\hline Lum * & Luminárias - MG & FES montana & $\mathrm{MA} / \mathrm{Ce}$ & $\mathrm{Cw}$ & Rodrigues et al. (2003) \\
\hline $\mathrm{Mdm} *$ & Madre de Deus de Minas - MG & FES montana & $\mathrm{MA} / \mathrm{Ce}$ & $\mathrm{Cw}$ & Oliveira-Filho \& Fontes (2000) \\
\hline Npo & Nova Ponte - MG & FES montana & $\mathrm{Ce}$ & Aw & Oliveira-Filho \& Fontes (2000) \\
\hline Oup & EE Tripuí, Ouro Preto - MG & FES altomontana & MA & $\mathrm{Cw}$ & $\begin{array}{l}\text { Pedralli et al. (2000), Werneck } \\
\text { et al. }(2000)\end{array}$ \\
\hline Pct* & Paracatu - MG & FES montana & $\mathrm{Ce}$ & Aw & Oliveira-Filho \& Fontes (2000) \\
\hline Pqm & $\begin{array}{l}\text { Serra do Curral, Belo Horizonte - } \\
\text { MG }\end{array}$ & FES montana & $\mathrm{MA} / \mathrm{Ce}$ & $\mathrm{Cw}$ & $\begin{array}{l}\text { Brandão (1992), Werneck (dados } \\
\text { não publicados) }\end{array}$ \\
\hline Prd & PE Rio Doce, Timóteo - MG & FES terras baixas & MA & Aw & Lopes et al. (2002) \\
\hline Rvs & Rio Vermelho e Serra Azul - MG & FES montana & MA & $\mathrm{Cw}$ & Oliveira-Filho \& Fontes (2000) \\
\hline Sam & $\begin{array}{l}\text { Serra do Ambrósio, Rio Vermelho } \\
-\mathrm{MG}\end{array}$ & FES altomontana & MA & $\mathrm{Cw}$ & Oliveira-Filho \& Fontes (2000) \\
\hline Sbr & Santa Bárbara - MG & FES submontana & MA & $\mathrm{Cw}$ & Oliveira-Filho \& Fontes (2000) \\
\hline $\mathrm{Scm}$ & Serra do Cipó - MG & FES altomontana & $\mathrm{Ce}$ & $\mathrm{Cw}$ & Meguro et al. (1996) \\
\hline Scs * & Serra da Canastra - MG & FES montana & $\mathrm{Ce}$ & Aw & Oliveira-Filho \& Fontes (2000) \\
\hline Srs * & Santa Rita do Sapucaí - MG & FES montana & MA & $\mathrm{Cw}$ & Brandão et al. (1998) \\
\hline
\end{tabular}


continua

\begin{tabular}{|c|c|c|c|c|c|}
\hline Código & Localização & Tipologia & Domínio & Clima & Fonte \\
\hline Svi & Santa Vitória - MG & FES submontana & $\mathrm{Ce}$ & Aw & Oliveira-Filho \& Fontes (2000) \\
\hline Tir & Tiradentes $-\mathrm{MG}$ & FES montana & $\mathrm{MA} / \mathrm{Ce}$ & $\mathrm{Cw}$ & Oliveira-Filho \& Fontes (2000) \\
\hline Tma * & Três Marias - MG & FES submontana & $\mathrm{Ce}$ & Aw & Oliveira-Filho \& Fontes (2000) \\
\hline Ufm & EE UFMG, Belo Horizonte - MG & FES montana & $\mathrm{MA} / \mathrm{Ce}$ & $\mathrm{Cw}$ & Kamino (2002) \\
\hline Upa * & EE Panga, Uberlândia - MG & FES montana & $\mathrm{Ce}$ & Aw & Oliveira-Filho \& Fontes (2000) \\
\hline Viç & Viçosa - MG & FES montana & MA & $\mathrm{Cw}$ & Silva et al. (2004) \\
\hline $\mathrm{Caf}^{*}$ & Cafuringa - DF & FES altomontana & $\mathrm{Ce}$ & Aw & Oliveira-Filho \& Fontes (2000) \\
\hline $\mathrm{Gcv} *$ & Gama, Cabeça de Veado - DF & FES altomontana & $\mathrm{Ce}$ & $\mathrm{Aw}$ & Oliveira-Filho \& Fontes (2000) \\
\hline $\operatorname{Ibg} *$ & RE IBGE - DF & FES montana & $\mathrm{Ce}$ & Aw & Silva-Júnior (2004) \\
\hline $\mathrm{Sad}^{*}$ & Santo Antônio do Descoberto - GO & FES montana & $\mathrm{Ce}$ & Aw & Oliveira-Filho \& Fontes (2000) \\
\hline Sil * & Silvânia - GO & FES montana & $\mathrm{Ce}$ & Aw & Oliveira-Filho \& Fontes (2000) \\
\hline Vpr * & Vila Propício - GO & FES montana & $\mathrm{Ce}$ & $\mathrm{Aw}$ & Oliveira-Filho \& Fontes (2000) \\
\hline Atb & PM Grota Funda, Atibaia - SP & FOD altomontana & MA & $\mathrm{Cf}$ & Oliveira-Filho \& Fontes (2000) \\
\hline Bau & Bauru - SP & FES submontana & $\mathrm{Ce}$ & $\mathrm{Cw}$ & Oliveira-Filho \& Fontes (2000) \\
\hline Cam & Campinas - SP & FES submontana & $\mathrm{MA} / \mathrm{Ce}$ & $\mathrm{Cw}$ & Oliveira-Filho \& Fontes (2000) \\
\hline $\mathrm{Cub}$ & Cubatão - SP & FOD terras baixas & MA & Af & Oliveira-Filho \& Fontes (2000) \\
\hline Gru & Guarulhos - SP & FOD montana & MA & $\mathrm{Cf}$ & Oliveira-Filho \& Fontes (2000) \\
\hline Ipe * & Ipeúna - SP & FES submontana & $\mathrm{Ce}$ & $\mathrm{Cw}$ & Bertani et al. (2001) \\
\hline Ita & Itatinga $-\mathrm{SP}$ & FES submontana & $\mathrm{Ce}$ & $\mathrm{CW}$ & Ivanauskas et al. (1999) \\
\hline $\mathrm{Jab}$ & UNESP, Jaboticabal - SP & FES submontana & $\mathrm{Ce}$ & $\mathrm{Cw}$ & Oliveira-Filho \& Fontes (2000) \\
\hline Jun & Serra do Japi, Jundiaí - SP & FOD montana & MA & $\mathrm{Cf}$ & Oliveira-Filho \& Fontes (2000) \\
\hline Jur & Juréia, Iguape - SP & FOD terras baixas & MA & Af & Oliveira-Filho \& Fontes (2000) \\
\hline $\operatorname{Mog} *$ & RB Mogi-Guaçu - SP & FES submontana & $\mathrm{MA} / \mathrm{Ce}$ & $\mathrm{Cw}$ & Oliveira-Filho \& Fontes (2000) \\
\hline Per & Peruíbe - SP & FOD terras baixas & MA & Af & Oliveira et al. (2001) \\
\hline Pfa & Paulo de Faria - SP & FES submontana & MA & $\mathrm{Cw}$ & Oliveira-Filho \& Fontes (2000) \\
\hline Rcl & Rio Claro - SP & FES submontana & MA & $\mathrm{Cw}$ & Oliveira-Filho \& Fontes (2000) \\
\hline Sca & São Carlos - SP & FES montana & $\mathrm{Ce}$ & $\mathrm{Cw}$ & Silva \& Soares (2002) \\
\hline $\mathrm{Sjc}$ & RF São José dos Campos - SP & FOD montana & MA & $\mathrm{Cf}$ & Oliveira-Filho \& Fontes (2000) \\
\hline Spa & São Paulo - SP & FOD montana & MA & $\mathrm{Cf}$ & Oliveira-Filho \& Fontes (2000) \\
\hline Uba & Ubatuba - SP & FOD terras baixas & MA & Af & Oliveira-Filho \& Fontes (2000) \\
\hline $\mathrm{Cma}$ & Cachoeira de Macuco - RJ & FOD terras baixas & MA & Af & Kurtz \& Araújo (2000) \\
\hline $\operatorname{Imb}$ & Imbé, Campos dos Goytacazes - RJ & FOD terras baixas & MA & $\mathrm{Aw}$ & Moreno et al. (2003) \\
\hline Itt & Itatiaia - RJ & FOD montana & MA & $\mathrm{Cw}$ & Oliveira-Filho \& Fontes (2000) \\
\hline Mca & $\begin{array}{l}\text { Mata do Carvão, São Francisco do } \\
\text { Itabapoana - RJ }\end{array}$ & FES terras baixas & MA & Aw & Silva \& Nascimento (2001) \\
\hline Mrc & Maricá - RJ & FOD terras baixas & MA & Aw & Oliveira-Filho \& Fontes (2000) \\
\hline Rio & Rio de Janeiro - RJ & FOD terras baixas & MA & Aw & Peixoto et al. (2004) \\
\hline $\mathrm{Sja}$ & Silva Jardim - RJ & FOD submontana & MA & Af & Borém \& Oliveira-Filho (2002) \\
\hline $\mathrm{Cba}$ & Conceição da Barra - ES & FOD terras baixas & MA & $\mathrm{Am}$ & Oliveira-Filho \& Fontes (2000) \\
\hline Lin & Linhares - ES & FOD terras baixas & MA & $\mathrm{Am}$ & Oliveira-Filho \& Fontes (2000) \\
\hline Ste & Santa Tereza - ES & FOD montana & MA & Aw & Oliveira-Filho \& Fontes (2000) \\
\hline
\end{tabular}

* = florestas ripárias / riparian forests. 
1989). Assim, a matriz final de dados binários para as análises multivariadas continha 73 áreas e 659 espécies que ocorreram em mais de cinco localidades.

A composição florística da floresta estudada foi avaliada através da influência dos principais domínios fitogeográficos brasileiros, por meio da distribuição das espécies nos domínios da Mata Atlântica, do Cerrado, da Caatinga e da Amazônia. A informação geográfica sobre as espécies baseou-se no banco de dados de Oliveira-Filho (2008). Para a delimitação dos domínios da Caatinga e da Amazônia considerou-se a delimitação do IBGE (2004).

Duas técnicas multivariadas foram utilizadas para analisar os dados compilados, objetivando uma investigação integrada para a detecção e interpretação dos padrões florísticos entre as 82 áreas que pudessem ser associados a variáveis geográfico-ambientais (Dargie 1984). A primeira técnica empregada foi uma ordenação por meio da análise de correspondência retificada (DCA - detrended correspondence analysis), que não necessita de suposição sobre distribuição de unidades de amostragem e de espécies no espaço ambiental estudado (McCune \& Grace 2002). A segunda técnica utilizada consistiu em uma classificação hierárquica aglomerativa pelo método de agrupamento por médias aritméticas não ponderadas (UPGMA), tendo como medida de similaridade entre as amostras o índice de Jaccard. Para a realização das análises multivariadas foi utilizado o programa PC-ORD for Windows versão 5 (McCune \& Mefford 1999).

\section{Resultados}

Nas amostragens realizadas no Vale dos Cristais, foram identificadas 203 espécies, pertencentes a 120 gêneros, representando 50 famílias, sendo seis taxa identificados somente em gênero e seis apenas em família (tabela 2). Desse total, 163 espécies foram registradas nas parcelas e 40 espécies no levantamento florístico. As famílias mais representativas em espécies foram Fabaceae (35), Myrtaceae (33 espécies), Lauraceae (12), Rubiaceae (9), Annonaceae (7), Bignoniaceae (6), Meliaceae (6) e Salicaceae (6), o que significa que cerca de um sexto do número de famílias concentra os maiores valores da riqueza de espécies $(56,2 \%$ do total). Quinze famílias $(30,0 \%)$ apresentaram uma única espécie, $16(32,0 \%)$ tiveram duas espécies, três $(6,0 \%)$ foram representadas por três espécies, duas $(4,0 \%)$ apresentaram quatro espécies e cinco $(10,0 \%)$ tiveram cinco espécies. Myrcia foi o que teve maior número de espécies (9), seguida de Casearia (6), Eugenia (6), Machaerium (6), Dalbergia (5), Inga (4) e Nectandra (4). Esses sete gêneros (5,8\% do total) foram responsáveis por quase um quinto das espécies registradas. Calyptranthes, Campomanesia,
Tabela 2. Listagem das espécies arbóreas registradas na floresta semidecídua do Vale dos Cristais, Município de Nova Lima, MG, com seus respectivos números de coletor do material coletado por M.S. Werneck incluído no Herbário BHCB. Distribuição. $($ Atl = Mata Atlântica; $\mathrm{Cer}=$ Cerrado; $\mathrm{Caa}=$ Caatinga; $\mathrm{Amz}=$ Amazônia $)$.

Table 2. Trees species found in the semideciduous forest located in the Vale dos Cristais, municipality of Nova Lima, Minas Gerais State, Brazil, with voucher number of M.S. Werneck included in the BHCB Herbarium. Distribution. (Atl $=$ Atlantic Rain Forest $;$ Cer $=$ Cerrado $;$ Caa $=$ Caatinga $;$ Amz $=$ Amazonian Rain Forest).

\begin{tabular}{|c|c|c|}
\hline Família / Espécie & Distribuição & Voucher \\
\hline \multicolumn{3}{|l|}{ 1.ANACARDIACEAE } \\
\hline $\begin{array}{l}\text { Astronium concinnum Schott } \\
\text { ex Spreng. }\end{array}$ & Atl & 293 \\
\hline $\begin{array}{l}\text { Lithraea molleoides (Vell.) } \\
\text { Engl. }\end{array}$ & Ampla & 73 \\
\hline Schinus terebinthifolius Raddi & Atl, Cer & \\
\hline Tapirira guianensis Aubl. & Ampla & 531 \\
\hline $\begin{array}{l}\text { Tapirira obtusa (Benth.) J. D. } \\
\text { Mitch. }\end{array}$ & Atl, Cer, Amz & 412 \\
\hline \multicolumn{3}{|l|}{ 2. ANNONACEAE } \\
\hline Duguetia sp. & - & 784 \\
\hline Guatteria odontopetala Mart. & Atl & 218 \\
\hline Guatteria sellowiana Schltdl. & Atl, Cer & 523 \\
\hline $\begin{array}{l}\text { Guatteria villosissima A. St.- } \\
\text { Hil. }\end{array}$ & Atl, Cer, Amz & 51 \\
\hline Rollinia laurifolia Schltdl. & Atl & 170 \\
\hline $\begin{array}{l}\text { Rollinia sylvatica (A. St.-Hil.) } \\
\text { Mart. }\end{array}$ & Atl, Cer & 281 \\
\hline $\begin{array}{l}\text { Xylopia aromatica (Lam.) } \\
\text { Mart. }\end{array}$ & Ampla & 711 \\
\hline \multicolumn{3}{|l|}{ 3. APOCYNACEAE } \\
\hline Aspidosperma discolor A. DC. & Ampla & 323 \\
\hline $\begin{array}{l}\text { Aspidosperma parvifolium A. } \\
\text { DC. }\end{array}$ & Atl & 856 \\
\hline \multicolumn{3}{|l|}{ 4.AQUIFOLIACEAE } \\
\hline \multicolumn{3}{|l|}{ 5. ARALIACEAE } \\
\hline $\begin{array}{l}\text { Dendropanax cuneatus (DC.) } \\
\text { Decne. \& Planch. }\end{array}$ & Atl, Cer & 111 \\
\hline $\begin{array}{l}\text { Schefflera vinosa (Cham. \& } \\
\text { Schltdl.) Frodin \& Fiaschi }\end{array}$ & Atl, Cer & \\
\hline \multicolumn{3}{|l|}{ 6. ARECACEAE } \\
\hline $\begin{array}{l}\text { Acrocomia aculeata (Jacq.) } \\
\text { Lodd. ex Mart. }\end{array}$ & Ampla & \\
\hline \multicolumn{3}{|l|}{ 7. ASTERACEAE } \\
\hline $\begin{array}{l}\text { Piptocarpha axillaris (Less.) } \\
\text { Baker }\end{array}$ & Atl, Cer & 816 \\
\hline Piptocarpha macropoda Baker & Atl, Cer & 511 \\
\hline
\end{tabular}


continua

\begin{tabular}{|c|c|c|}
\hline Família / Espécie & Distribuição & Voucher \\
\hline $\begin{array}{l}\text { Vernonanthura divaricata } \\
\text { (Spreng.) H. Rob. }\end{array}$ & Atl, Cer & \\
\hline 8. BIGNONIACEAE & & \\
\hline $\begin{array}{l}\text { Cybistax antisyphilitica (Mart.) } \\
\text { Mart. }\end{array}$ & Atl, Cer, Amz & 327 \\
\hline Jacaranda macrantha Cham. & Atl, Cer & \\
\hline $\begin{array}{l}\text { Sparattosperma leucanthum } \\
\text { (Vell.) K.Schum. }\end{array}$ & Atl, Cer, Amz & 314 \\
\hline $\begin{array}{l}\text { Tabebuia heptaphylla (Vell.) } \\
\text { Toledo }\end{array}$ & Ampla & \\
\hline $\begin{array}{l}\text { Tabebuia ochracea (Cham.) } \\
\text { Standl. }\end{array}$ & Ampla & \\
\hline $\begin{array}{l}\text { Tabebuia serratifolia (Vahl) } \\
\text { Nicholson }\end{array}$ & Ampla & 524 \\
\hline 9. BORAGINACEAE & & \\
\hline $\begin{array}{l}\text { Cordia sellowiana Cham. } \\
\text { 10. BURSERACEAE }\end{array}$ & Atl, Cer, Amz & 256 \\
\hline $\begin{array}{l}\text { Protium heptaphyllum (Aubl.) } \\
\text { Marchand }\end{array}$ & Ampla & 122 \\
\hline $\begin{array}{l}\text { Protium spruceanum (Benth.) } \\
\text { Engl. }\end{array}$ & Atl, Cer, Amz & 357 \\
\hline 11. CANNABACEAE & & \\
\hline $\begin{array}{l}\text { Celtis brasiliensis (Gardner) } \\
\text { Planch. }\end{array}$ & Ampla & \\
\hline $\begin{array}{l}\text { Trema micrantha (L.) Blume } \\
\text { 12. CELASTRACEAE }\end{array}$ & Ampla & \\
\hline $\begin{array}{l}\text { Maytenus evonymoides } \\
\text { Reissek }\end{array}$ & Atl, Cer & \\
\hline Maytenus gonoclada Mart. & Atl, Cer & 690 \\
\hline Maytenus salicifolia Reissek & Atl, Cer & 399 \\
\hline $\begin{array}{l}\text { Salacia elliptica (Mart. ex } \\
\text { Schult.) G. Don }\end{array}$ & Ampla & 397 \\
\hline 13. CHRYSOBALANACEAE & & \\
\hline $\begin{array}{l}\text { Licania octandra (Hoffmanns. } \\
\text { ex Roem. \& Schult.) Kuntze }\end{array}$ & Atl, Cer, Amz & 150 \\
\hline 14. CLETHRACEAE & & \\
\hline $\begin{array}{l}\text { Clethra scabra Pers. } \\
\text { 15. CLUSIACEAE }\end{array}$ & Atl, Cer & 588 \\
\hline $\begin{array}{l}\text { Kielmeyera coriacea Mart. \& } \\
\text { Zucc. }\end{array}$ & Atl, Cer & 97 \\
\hline 16. COMBRETACEAE & & \\
\hline $\begin{array}{l}\text { Terminalia glabrescens Mart. } \\
\text { 17. CUNONIACEAE }\end{array}$ & Atl, Cer, Amz & 337 \\
\hline $\begin{array}{l}\text { Lamanonia ternata Vell. } \\
\text { 18. CYATHEACEAE }\end{array}$ & Atl, Cer & 467 \\
\hline $\begin{array}{l}\text { Cyathea delgadii Sternb. } \\
\text { 19. EUPHORBIACEAE }\end{array}$ & Ampla & \\
\hline $\begin{array}{l}\text { Alchornea glandulosa Poepp. } \\
\text { \& Endl. }\end{array}$ & Ampla & 204 \\
\hline Croton floribundus Spreng. & Atl, Cer & 541 \\
\hline Croton urucurana Baill. & Ampla & 343 \\
\hline
\end{tabular}

continua

\begin{tabular}{|c|c|c|}
\hline Família / Espécie & Distribuição & Vouche \\
\hline $\begin{array}{l}\text { Pera glabrata (Schott) Poepp. } \\
\text { ex Baill. }\end{array}$ & Atl, Cer, Amz & 107 \\
\hline $\begin{array}{c}\text { Sebastiania commersoniana } \\
\text { (Baill.) L.B.Sm. \& Downs }\end{array}$ & Ampla & 266 \\
\hline \multicolumn{3}{|l|}{ 20. FABACEAE } \\
\hline Acacia polyphylla DC. & Ampla & 922 \\
\hline $\begin{array}{l}\text { Acosmium dasycarpum (Vogel) } \\
\text { Yakovlev }\end{array}$ & Atl, Cer & 104 \\
\hline $\begin{array}{l}\text { Anadenanthera colubrina } \\
\text { (Vell.) Brenan }\end{array}$ & Ampla & 855 \\
\hline $\begin{array}{l}\text { Apuleia leiocarpa (Vogel) J. F. } \\
\text { Macbr. }\end{array}$ & Ampla & 634 \\
\hline $\begin{array}{l}\text { Bauhinia longifolia (Bong.) D. } \\
\text { Dietr. }\end{array}$ & Atl, Cer & 709 \\
\hline Bowdichia virgilioides Kunth & Ampla & 544 \\
\hline $\begin{array}{l}\text { Cassia ferruginea (Schrad.) } \\
\text { Schrad. ex DC. }\end{array}$ & Atl, Cer & \\
\hline Cenostigma sp. & - & 931 \\
\hline Copaifera langsdorffii Desf. & Ampla & 72 \\
\hline Dalbergia brasiliensis Vogel & Atl & 577 \\
\hline Dalbergia foliolosa Benth. & Atl, Cer & 469 \\
\hline $\begin{array}{l}\text { Dalbergia frutescens (Vell.) } \\
\text { Britton }\end{array}$ & Atl, Cer, Caa & 574 \\
\hline Dalbergia miscolobium Benth. & Atl, Cer & 55 \\
\hline Dalbergia nigra (Vell.) & Atl & 833 \\
\hline
\end{tabular}

Allemão ex Benth.

Hymenaea stigonocarpa Mart. Atl, Cer ex Hayne

Inga cylindrica (Vell.) Mart. Atl, Cer, Amz

Inga edulis Mart.

Atl, Cer, Amz 614

Inga flagelliformis (Vell.) Mart. Atl, Amz 421

Inga sessilis (Vell.) Mart.

Atl

246

Leucochloron incuriale (Vell.) Atl, Cer

Barneby \& J. W. Grimes

Machaerium brasiliense Vogel

Atl, Cer

466

Machaerium nictitans (Vell.)

Benth.

Machaerium scleroxylon Tul.

Machaerium sp.

Machaerium stipitatum (DC.)

Vogel

Machaerium villosum Vogel

Mimosa caesalpiniifolia Benth.

Piptadenia adiantoides

(Spreng.) J. F. Macbr.

Piptadenia gonoacantha

(Mart.) J. F. Macbr.

Platycyamus regnellii Benth.

Platypodium elegans Vogel

Senna macranthera (Collad.)

H. S. Irwin \& Barneby
Ampla 606

Atl, Cer $\quad 879$

- $\quad 545$

Atl, Cer $\quad 381$

Atl, Cer $\quad 50$

Atl, Caa

Atl

Atl, Cer 284

Atl, Cer $\quad 842$

Ampla 542

Atl, Cer, Caa 
continua

\begin{tabular}{|c|c|c|}
\hline Família / Espécie & Distribuição & Voucher \\
\hline $\begin{array}{l}\text { Senna multijuga (L. C. Rich.) } \\
\text { H. S. Irwin \& Barneby }\end{array}$ & Ampla & 708 \\
\hline Swartzia pilulifera Benth. & Atl, Cer & 480 \\
\hline $\begin{array}{l}\text { Tachigali rugosa (Mart. ex } \\
\text { Benth.) Zarucchi \& Pipoly }\end{array}$ & Atl, Cer, Amz & \\
\hline 21.HYPERICACEAE & & \\
\hline $\begin{array}{l}\text { Vismia brasiliensis Choisy } \\
\text { 22. LAMIACEAE }\end{array}$ & Atl, Cer & 496 \\
\hline Aegiphila sellowiana Cham. & Atl, Cer & \\
\hline $\begin{array}{l}\text { Hyptidendron asperrimum } \\
\text { (Epling) Harley }\end{array}$ & Atl & 318 \\
\hline Vitex sellowiana Cham. & Atl & 529 \\
\hline 23. LAURACEAE & & \\
\hline Aniba canelilla (Kunth) Mez & Atl, Amz & 217 \\
\hline $\begin{array}{l}\text { Aniba firmula (Nees \& Mart.) } \\
\text { Mez }\end{array}$ & Atl & 939 \\
\hline $\begin{array}{l}\text { Cinnamomum tomentulosum } \\
\text { Kosterm. }\end{array}$ & Atl & 667 \\
\hline $\begin{array}{l}\text { Nectandra megapotamica } \\
\text { (Spreng.) Mez }\end{array}$ & Atl, Cer & 288 \\
\hline Nectandra nitidula Nees & Atl, Cer & 187 \\
\hline Nectandra oppositifolia Nees & Ampla & 298 \\
\hline $\begin{array}{l}\text { Nectandra reticulata (Ruiz \& } \\
\text { Pav.) Mez }\end{array}$ & Ampla & 916 \\
\hline $\begin{array}{l}\text { Ocotea diospyrifolia (Meisn.) } \\
\text { Mez }\end{array}$ & Ampla & \\
\hline Ocotea pulchella Mart. & Atl, Cer & 134 \\
\hline Ocotea spixiana (Nees) Mez & Atl, Cer & 319 \\
\hline Lauraceae 1 & - & 725 \\
\hline Lauraceae 2 & - & 894 \\
\hline 24. MALPIGHIACEAE & & \\
\hline Byrsonima stipulacea A. Juss. & Atl, Amz & 344 \\
\hline Malpighiaceae 1 & - & 808 \\
\hline 25. MALVACEAE & & \\
\hline Guazuma ulmifolia Lam. & Ampla & \\
\hline $\begin{array}{l}\text { Luehea grandiflora Mart. \& } \\
\text { Zucc. }\end{array}$ & Ampla & 121 \\
\hline 26. MELASTOMATACEAE & & \\
\hline Leandra scabra DC. & Atl & \\
\hline $\begin{array}{l}\text { Miconia cinnamomifolia (DC.) } \\
\text { Naudin }\end{array}$ & Atl, Cer & 462 \\
\hline Miconia eichleri Cogn. & Atl & \\
\hline $\begin{array}{l}\text { Tibouchina candolleana (Mart. } \\
\text { ex DC.) Cogn. }\end{array}$ & Atl, Cer & 216 \\
\hline $\begin{array}{l}\text { Tibouchina granulosa Cogn. } \\
\text { 27. MELIACEAE }\end{array}$ & Atl & 313 \\
\hline $\begin{array}{l}\text { Cabralea canjerana (Vell.) } \\
\text { Mart. }\end{array}$ & Ampla & 493 \\
\hline Cedrela fissilis Vell. & Ampla & 867 \\
\hline Guarea guidonia (L.) Sleumer & Ampla & 622 \\
\hline Guarea macrophylla Vahl & Ampla & 392 \\
\hline
\end{tabular}

continua

\begin{tabular}{|c|c|c|}
\hline Família / Espécie & Distribuição & Voucher \\
\hline Trichilia catigua A. Juss. & Atl, Cer & 410 \\
\hline Trichilia pallida $\mathrm{Sw}$. & Ampla & 583 \\
\hline 28. MONIMIACEAE & & \\
\hline $\begin{array}{l}\text { Mollinedia argyrogyna } \\
\text { Perkins }\end{array}$ & Atl, Cer & 415 \\
\hline Mollinedia sp. & - & 405 \\
\hline
\end{tabular}

29. MORACEAE

Brosimum guianense (Aubl.) Atl, Amz 487

Huber

Ficus enormis (Mart. ex Miq.) Ampla Mart.

Ficus pertusa L. f.

Naucleopsis oblongifolia

(Kuhlm.) Carauta

Sorocea bonplandii (Baill.) W. Atl, Cer

C. Burger et al.

30. MYRSINACEAE

Myrsine matensis (Mez) Cer

Otegui

31. MYRTACEAE

Calycorectes sp.

Calyptranthes clusiifolia

O.Berg

Calyptranthes concinna DC.

Ampla $\quad 499$

Atl 153

Calyptranthes lucida Mart. ex Atl, Cer, Amz

262

DC.

Campomanesia guaviroba

(DC.) Kiaersk.

Campomanesia guazumifolia

(Cambess.) O. Berg

Campomanesia hirsuta

Gardner

Eugenia aurata O. Berg

Eugenia bocainensis Mattos

Eugenia calycina Cambess.

Eugenia cuprea (O. Berg)

Nied.

Eugenia curvato-petiolata

Kiaersk.

Eugenia florida DC.

Myrcia hebepetala DC.

Myrcia lindeniana (O. Berg)

C. Wright

Marlierea clausseniana $(\mathrm{O}$.

Berg) Kiaersk.

Marlierea sp.

$\begin{array}{ll}- & 428\end{array}$

Atl, Cer $\quad 175$

Atl

Atl $\quad 933$

Atl, Cer $\quad 845$

Atl $\quad 145$

Atl, Cer, Caa 562

Atl 571

Cer $\quad 943$

Atl 280

Atl $\quad 589$

Ampla $\quad 873$

Atl, Cer

Ampla

Atl, Cer $\quad 94$

$\begin{array}{ll}- & 257\end{array}$

Myrcia retorta Cambess. Atl

Myrcia amazonica DC. Ampla

Myrcia splendens (Sw.) DC. Ampla

Myrcia guianensis (Aubl.) DC.

Myrcia rufipes DC.
118

347

Atl, Cer 253

continuação 
continua

\begin{tabular}{|c|c|c|}
\hline Família / Espécie & Distribuição & Voucher \\
\hline Myrcia tomentosa (Aubl.) DC. & Ampla & 535 \\
\hline Myrcia venulosa DC. & Atl, Cer & 819 \\
\hline $\begin{array}{l}\text { Myrciaria glanduliflora } \\
\text { (Kiaersk.) Mattos \& D. } \\
\text { Legrand }\end{array}$ & Atl, Cer & 248 \\
\hline $\begin{array}{l}\text { Pimenta pseudocaryophyllus } \\
\text { (Gomes) Landrum }\end{array}$ & Atl, Cer & 455 \\
\hline Psidium rufum DC. & Atl, Cer, Caa & 286 \\
\hline $\begin{array}{l}\text { Psidium sartorianum (O. Berg) } \\
\text { Nied. }\end{array}$ & Ampla & 271 \\
\hline $\begin{array}{l}\text { Siphoneugena densiflora O. } \\
\text { Berg }\end{array}$ & Atl, Cer & 600 \\
\hline $\begin{array}{l}\text { Siphoneugena widgreniana } \mathrm{O} \text {. } \\
\text { Berg }\end{array}$ & Atl, Cer & \\
\hline Myrtaceae 1 & - & 331 \\
\hline Myrtaceae 2 & - & 723 \\
\hline Myrtaceae 3 & - & 733 \\
\hline \multicolumn{3}{|l|}{ 32. NYCTAGINACEAE } \\
\hline $\begin{array}{l}\text { Guapira graciliflora (Schmidt) } \\
\text { Lundell }\end{array}$ & Atl, Cer & \\
\hline Guapira noxia (Netto) Lundell & Atl, Cer, Caa & \\
\hline Guapira opposita (Vell.) Reitz & Atl, Cer, Amz & 163 \\
\hline $\begin{array}{l}\text { Neea floribunda Poepp. \& } \\
\text { Endl. }\end{array}$ & Atl, Amz & \\
\hline 33. PHYLLANTHACEAE & & \\
\hline $\begin{array}{l}\text { Hieronyma alchorneoides } \\
\text { Allemão }\end{array}$ & Ampla & 141 \\
\hline
\end{tabular}

34. PIPERACEAE

Piper aduncum L. Ampla

35. PODOCARPACEAE

Podocarpus sellowii Klotzsch Atl, Cer, Amz ex Endl.

36. PROTEACEAE

Roupala montana Aubl. Ampla $\quad 679$

37. RHAMNACEAE

Rhamnidium elaeocarpum

Reissek

38. RUBIACEAE

Cordiera sessilis (Vell.) Atl, Cer, Caa

Kuntze

Amaioua guianensis Aubl.

Coutarea hexandra (Jacq.) $\mathrm{K}$.

Schum.

Faramea hyacinthina Mart.

Guettarda viburnoides Cham. \& Schltdl.

Rudgea sessilis (Vell.) Müll.

Arg.

Psychotria stachyoides Benth.

Rudgea blanchetiana Müll.

Arg.

Atl $\quad 753$

Atl, Cer, Caa

Atl

Atl $\quad 249$ continua

\begin{tabular}{llc} 
Família / Espécie & Distribuição & Voucher \\
\hline Rudgea viburnoides (Cham.) & Atl, Cer & \\
Benth. & & \\
39. RUTACEAE & Atl, Cer \\
Esenbeckia febrifuga (A. St.- & & \\
Hil.) A. Juss. ex Mart. & & \\
Zanthoxylum rhoifolium Lam. & Ampla & \\
40. SALICACEAE & & \\
Casearia arborea (Rich.) Urb. & Ampla & 202 \\
Casearia decandra Jacq. & Ampla & 26 \\
Casearia lasiophylla Eichler & Atl, Cer & 704 \\
Casearia mariquitensis Kunth & Atl, Amz & 58 \\
Casearia obliqua Spreng. & Atl, Cer & 338 \\
Casearia sylvestris Sw. & Ampla & 143 \\
41. SAPINDACEAE & & \\
Cupania oblongifolia Mart. & Atl, Cer & 275 \\
Cupania vernalis Cambess. & Ampla & 61 \\
Matayba elaeagnoides Radlk. & Atl & 67 \\
Matayba guianensis Aubl. & Ampla & 285 \\
Matayba mollis Radlk. & Atl & 488 \\
42. SAPOTACEAE & & \\
Chrysophyllum gonocarpum & Ampla & \\
(Mart. \& Eichler) Engl. & & \\
Pouteria caimito (Ruiz \& Pav.) & Ampla & 185
\end{tabular}

Radlk.

Pouteria torta (Mart.) Radlk. Atl, Cer, Amz

43. SIPARUNACEAE

Siparuna brasiliensis (Spreng.) Atl, Cer

A. DC.

Siparuna guianensis Aubl. Ampla

201

44. SOLANACEAE

Solanum cernuum Vell.

Solanum granulosoleprosum

Atl, Cer

Ampla

Dunal

45. STYRACACEAE

Styrax acuminatus Pohl

Styrax camporum Pohl

46. THYMELAEACEAE

Daphnopsis brasiliensis Mart. Atl, Cer 261 \& Zucc.

47. URTICACEAE

Cecropia glaziovii Snethl. Atl, Cer

Cecropia hololeuca Miq. Atl

Urera baccifera (L.) Gaudich. Ampla

ex Wedd.

48. VERBENACEAE

Aloysia virgata (Ruiz \& Pav.) Ampla

A. Juss.

49. VOCHYSIACEAE

Vochysia rufa Mart.

Atl, Cer

Vochysia tucanorum Mart.

Atl, Cer

664
Atl, Cer 
Guapira, Guatteria, Matayba, Maytenus, Ocotea, Rudgea e Tabebuia apresentaram 3 espécies e os demais gêneros ( $86,7 \%$ do total) foram representados por uma ( 78 gêneros) ou duas (26 gêneros) espécies. Dentre as espécies registradas, uma é Pteridophyta (Cyathea delgadii - Cyatheaceae), uma é Gimnosperma (Podocarpus sellowii-Podocarpaceae) e as demais são angiospermas, sendo apenas uma delas monocotiledônea (Acrocomia aculeata-Arecaceae).

Trinta espécies arbóreas registradas no Vale dos Cristais (cerca de 16\% do total) possuem distribuição restrita ao Domínio da Mata Atlântica, duas espécies (1\%) são de ocorrência exclusiva do Cerrado (tabela 2) e 67 espécies (35\%) possuem distribuição em ambos os domínios supracitados. Sessenta espécies (pouco mais de 31\%) foram consideradas de ampla distribuição, por ocorrerem na Mata Atlântica e em outros domínios fitogeográficos do Brasil e da América Latina. As demais espécies (32 ou cerca de $17 \%$ ) possuem distribuição na Mata Atlântica e nos domínios da Amazônia, da Caatinga e/ou do Cerrado.

O resultado da análise de correspondência retificada (DCA) pode ser visualizado na figura 1 , cujos dois primeiros eixos da DCA sintetizaram cerca de $47 \%$ da variação total dos dados. Mesmo assim, o eixo 1 apresentou um autovalor $(0,308)$ mais elevado que o eixo $2(0,174)$, implicando em um gradiente mais evidente. O primeiro eixo da DCA explicou $28,9 \%$ da variação dos dados, sendo visível a separação das florestas em função do distanciamento do mar, tendo as florestas semidecíduas do Brasil Central à esquerda da figura 1 e as florestas ombrófilas litorâneas (SP, RJ e ES) à direita da mesma. O eixo 2 da DCA (variância de $17,6 \%$ ) foi relacionado, pelo menos parcialmente, com a altitude, separando, acima, as florestas estacionais semideciduais submontanas, presentes principalmente em São Paulo e, abaixo, as florestas estacionais semideciduais altimontanas. As florestas ombrófilas se enquadraram numa posição intermediária entre os extremos altitudinais da floresta semidecídua, não mostrando qualquer relação visível com a altitude. As áreas de floresta semidecídua ripárias e não ripárias apresentaram-se misturadas entre si, sem qualquer padrão aparente.

No dendrograma produzido pelo método de UPGMA podem ser visualizados três grupos distintos (figura 2). O primeiro grupo foi composto, em sua grande maioria, pelas florestas semidecíduas altimontanas e montanas da Mata Atlântica e de sua transição com o Cerrado em São Paulo e Minas Gerais, como o caso da área estudada

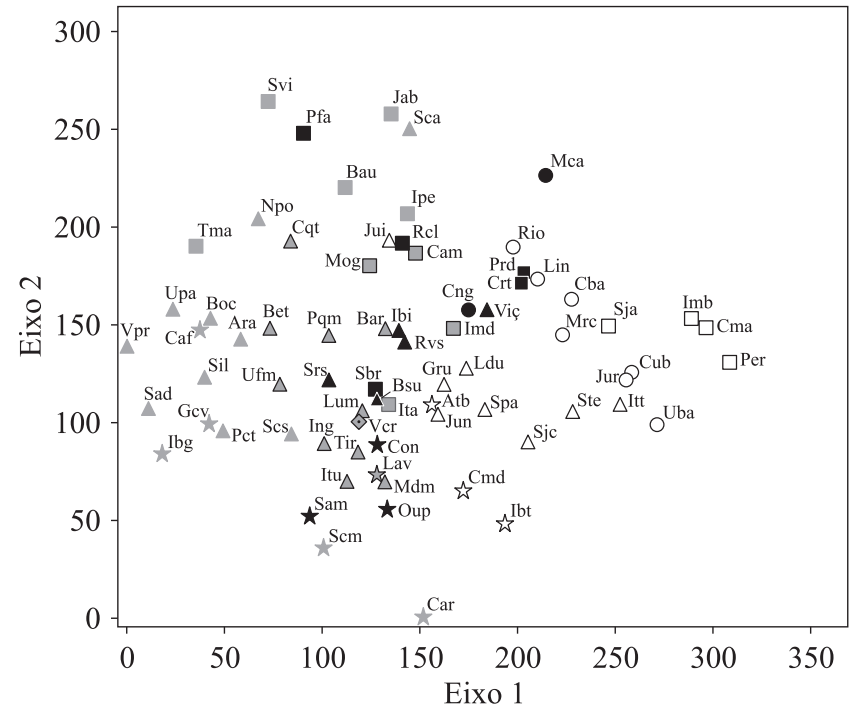

Figura 1. Diagrama de ordenação da análise de correspondência retificada (DCA) dos dados florísticos das 73 áreas de floresta semidecídua (FES) e ombrófila densa (FOD). As áreas estão identificadas pelos seus códigos na tabela 1. Símbolos com borda preta e sem preenchimento = FOD na Mata Atlântica; símbolos totalmente pretos = FES presente na Mata Atlântica; símbolos totalmente cinzas $=$ FES presente no Cerrado; símbolos com borda preta e preenchimento cinza $=$ FES presente na transição Mata Atlântica/Cerrado. ( $\mathrm{O}=$ florestas de terras baixas; $\square=$ florestas submontanas; $\Delta=$ florestas montanas; $i=$ florestas altimontana; $\diamond=$ FES, presente trabalho).

Figure 1. Dentrened Components Analysis ordination diagram (DCA) based on the floristic checklist for the 73 areas of semideciduous (FES) and Atlantic rain forest (FOD). Forest areas are identified by their three-letter codes in table 1. Open symbols $=$ FOD in Mata Atlântica Dominium; filled black symbols $=$ FES in Mata Atlântica Dominium; filled grey symbols $=$ FES in Cerrado Dominium; filled grey symbols with solid black lines $=$ FES from Mata Atlântica/Cerrado ecotone or enclave. $(\mathrm{O}=$ lowland forests; $\square=$ submontane forests; $\Delta=$ lower montane forests; $=$ upper montane forests; $\diamond=$ FES, present work).

no presente trabalho, além das florestas ombrófilas densas montanas e altimontanas do interior de São Paulo e florestas semidecíduas do Cerrado paulista. O grupo seguinte continha, principalmente, as florestas semidecíduas presentes nas áreas do Cerrado do Distrito Federal, Goiás e Minas Gerais e nos trechos de transição deste com a Mata Atlântica de Minas Gerais. Por fim, o terceiro agrupamento foi constituído basicamente pelas florestas ombrófilas densas litorâneas de São Paulo, Rio de Janeiro e Espírito Santo. Novamente, 


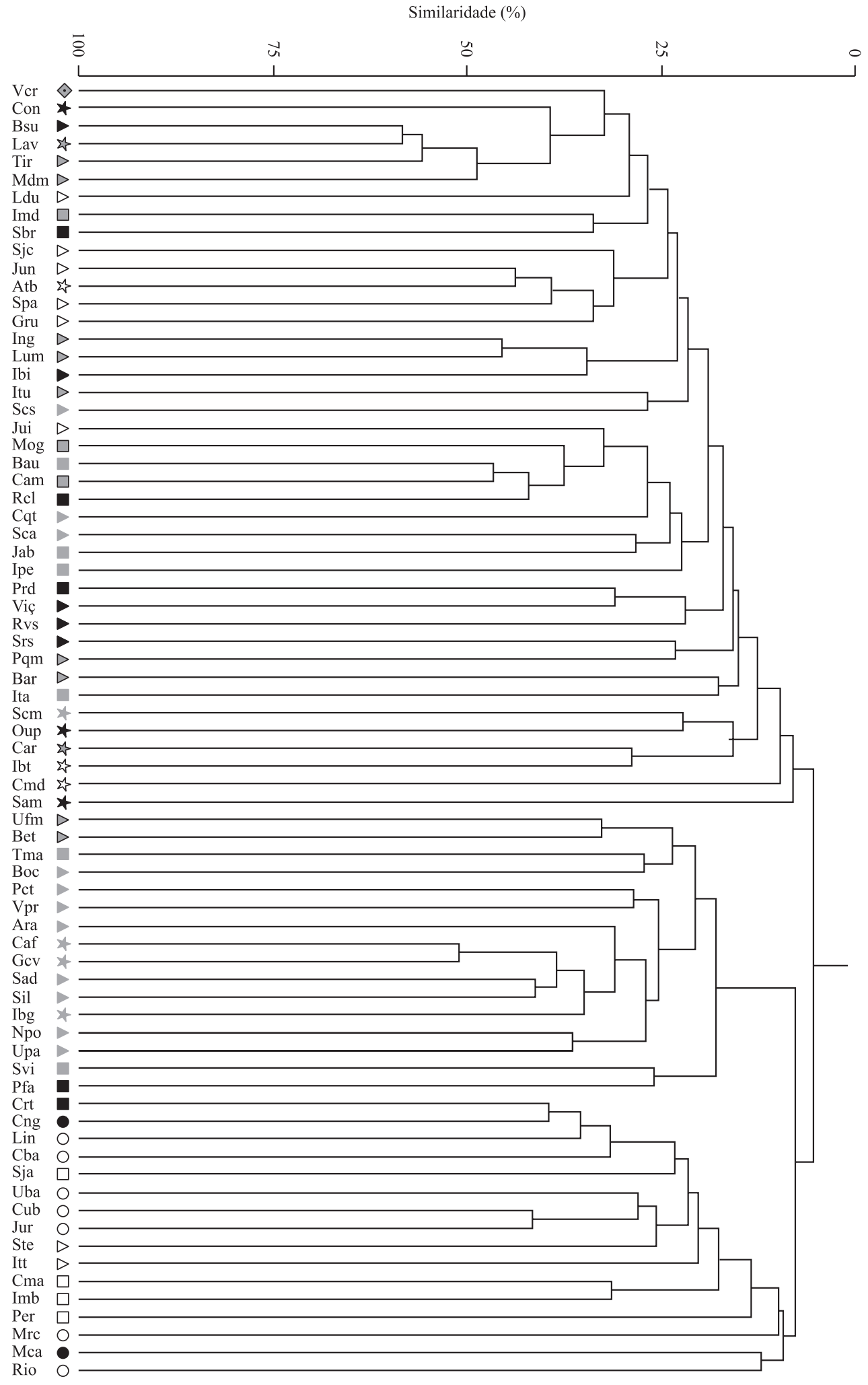

Figura 2. Dendrograma representando os agrupamentos das 73 áreas de floresta semidecídua (FES) e ombrófila densa (FOD), obtidas pelo método de UPGMA, com base na similaridade de Jaccard. As áreas estão identificadas pelos seus códigos na tabela 1. Símbolos com borda preta e sem preenchimento $=$ FOD na Mata Atlântica; símbolos totalmente pretos $=$ FES presente na Mata Atlântica; símbolos totalmente cinzas = FES presente no Cerrado; símbolos com borda preta e preenchimento cinza $=$ FES presente na transição Mata Atlântica/Cerrado. $(O=$ florestas de terras baixas; $\square=$ florestas submontanas;

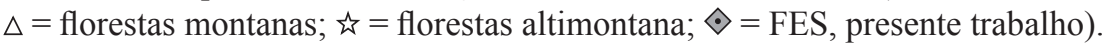


as florestas ripárias e não ripárias não apresentaram qualquer relação aparente, estando misturadas entre os três grupos.

\section{Discussão}

Avaliando as principais famílias botânicas registradas no presente estudo, em termos de riqueza de espécies, pode ser observado que o perfil florístico da floresta semidecídua do Vale dos Cristais apresenta um vínculo com o Domínio da Mata Atlântica mais forte que o do Cerrado. Embora Fabaceae, Myrtaceae, Rubiaceae, Melastomataceae e Euphorbiaceae sejam representativas de ambos os domínios, outras famílias representativas na floresta estudada, como Lauraceae, Moraceae e Annonaceae, são típicas das florestas semidecíduas e ombrófilas do Domínio da Mata Atlântica (Oliveira-Filho \& Fontes 2000). Essas mesmas famílias também são citadas por Leitão-Filho (1982) como as mais importantes para as florestas semidecíduas e ombrófilas do Estado de São Paulo. Asteraceae, Rutaceae e Sapotaceae, que também são bem representativas nas florestas semidecíduas e ombrófilas da Mata Atlântica (Oliveira-Filho \& Fontes 2000), apresentam uma representatividade intermediária na floresta semidecídua do Vale dos Cristais, embora não apareçam entre as dez mais importantes. Cabe ressaltar, ainda, que Peixoto \& Gentry (1990) afirmaram que Myrtaceae assume uma grande importância ecológica nas florestas ombrófilas da costa atlântica do Brasil, onde é encontrada com grande riqueza de espécies e abundância. Já Anacardiaceae, que figura entre as dez famílias com maior riqueza específica na área de estudo, é uma das 20 mais importantes no domínio do Cerrado (Ratter et al. 2003), exemplificando o único laço com esse domínio.

Em nível de gêneros, o perfil florístico da floresta semidecídua do Vale dos Cristais também apresenta um vínculo mais forte com o domínio da Mata Atlântica do que com o do Cerrado. Machaerium, Casearia e Ocotea, expressivos na área de estudo, estão bem representadas em ambos os domínios, mas de uma forma bem menos expressiva no Cerrado (Ratter et al. 2003). Já Inga, Maytenus, Guatteria e Nectandra são bastante representativos na Mata Atlântica e figuram entre os dez gêneros com maior riqueza de espécies na área de estudo. Myrcia e Eugenia figuram entre as mais típicas de ambos os domínios e, também, são as mais representativas na área de estudo. Dentre outros gêneros característicos das florestas semidecíduas e ombrófilas do domínio da Mata Atlântica (Oliveira-Filho \& Fontes 2000), como Erythroxylum, Ficus, Ilex, Marlierea, Mollinedia, Pouteria e Tibouchina, apenas o primeiro não foi registrado na floresta semidecídua do Vale dos Cristais e os demais estão representados por uma ou duas espécies.

A distribuição das espécies por domínio fitogeográfico também revela que o perfil florístico da floresta estudada apresenta uma relação maior com a Mata Atlântica, em função do número de espécies exclusivas da Mata Atlântica ser 15 vezes maior que as do Cerrado. O fato da maior parte das espécies apresentarem distribuição mais extensa também é verificado por Giulietti \& Pirani (1988) que observaram que essas espécies geralmente constituem grande parte da flora de várias áreas.

As análises multivariadas revelaram que existe um padrão de distribuição florística para as 73 áreas de florestas semidecíduas e ombrófilas consideradas no presente trabalho. Esse padrão está relacionado com a altitude e o distanciamento do mar, que é avaliado pelo caráter ombrófilo e semidecíduo das florestas presentes nas latitudes e longitudes abrangidas no presente estudo, pois à medida que se penetra mais para o interior do continente a estacionalidade climática se acentua em função do aumento da duração e/ou severidade da estação seca. Resultado semelhante foi identificado por van den Berg \& Oliveira-Filho (2000), Ivanauskas et al. (2000), Oliveira-Filho \& Ratter (2000), que afirmaram ser consistente a distinção entre as florestas semidecíduas e ombrófilas, uma vez que este padrão florístico está vinculado principalmente à sazonalidade da precipitação. No entanto, esta distinção não teria um caráter de substituição abrupta, mas de um contínuo onde predomina a supressão gradativa de espécies mais vinculadas ao clima pluvial na medida em que aumenta a duração da estação seca (Oliveira-Filho \& Fontes 2000). A variação dos dados na análise de DCA sugere, ainda, a ocorrência de gradientes curtos, onde grande parte

Figure 2. Dendrograms produced by group averaging (UPGMA) of Jaccard's floristic similarity of the 73 areas of semideciduous (FES) and Atlantic rain forest (FOD). Forest areas are identified by their three-letter codes in table 1. Open symbols $=$ FOD in Mata Atlântica Dominium; filled black symbols = FES in Mata Atlântica Dominium; filled grey symbols = FES in Cerrado Dominium; filled grey symbols with solid black lines = FES from Mata Atlântica/Cerrado ecotone or enclave. $(\mathrm{O}=$ lowland

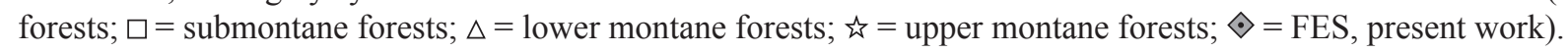


das espécies se distribui ao longo de todo o gradiente e poucas estão agrupadas em zonas particulares do mesmo (ter Braak 1995).

Além do mais, a flora arbórea das florestas semidecíduas, mesmo aquelas presentes no domínio do Cerrado, pode ser considerada um subconjunto da flora das florestas ombrófilas atlânticas, tendo espécies que, provavelmente, são mais eficientes em resistir e competir sob condições de seca mais prolongada (Oliveira-Filho et al. 2006). Espécies típicas da floresta ombrófila atlântica poderiam expandir sua distribuição pelo interior por meio das calhas dos rios via florestas ripárias e se estabelecerem localmente (Oliveira-Filho \& Ratter 2000). Cabe ressaltar, que a rede dendrítica de floresta ripárias no Cerrado é muito dependente da maior umidade dos fundos de vales, recebendo influência das florestas ombrófilas atlântica e amazônica (Oliveira-Filho \& Ratter 1995), embora haja pouco fundamento florístico para se pensar nas florestas ombrófilas atlânticas como mais próximas de suas correspondentes amazônicas do que de suas vizinhas semidecíduas (Oliveira-Filho \& Fontes 2000). De fato, a flora do Cerrado possui uma influência muito maior do domínio da Mata Atlântica do que da Amazônia, provavelmente devido às flutuações climáticas do Quaternário, dentre outros fatores, que influenciaram os ciclos de expansão e contração das formações abertas e florestas úmidas (Méio et al. 2003). Considerando os dois eixos da DCA em separado, averiguou-se que o eixo 1 apresentou um autovalor bem superior ao eixo 2 , indicando um gradiente bem mais forte no primeiro, sugerindo que o caráter ombrófilo e semidecíduo das florestas, relacionado com o distanciamento do mar, foi bem mais evidente que a influência da altitude. As variações altitudinais das florestas ombrófilas e semidecíduas tem sido um dos padrões mais claramente identificados em diversas regiões do Brasil (OliveiraFilho et al. 1994, Salis et al. 1995, Torres et al. 1997, Ivanauskas et al. 2000, Oliveira-Filho \& Fontes 2000, Scudeller et al. 2001, Ferraz et al. 2004, Peixoto et al. 2004).

As florestas semidecíduas mineiras se agruparam basicamente em dois grupos, sendo um composto pelas florestas semidecíduas do domínio do Cerrado e, portanto, de maior interioridade continental, e outro constituído pelas florestas semidecíduas do domínio Mata Atlântica. As florestas semidecíduas presentes nas áreas de contato entre os dois domínios se diferenciaram em função basicamente da conformação do relevo e da altitude. As florestas altimontanas, como Car e Lav (ver códigos na tabela 1), e as florestas montanas presentes nas áreas de relevo muito declivoso, como Pqm, Tir e Vcr (presente estudo), apresentaram maior similaridade com as florestas semidecíduas do domínio da Mata Atlântica. Já as florestas montanas cujo relevo é pouco declivoso, como Bet e Ufm, tiveram uma similaridade maior com as florestas semidecíduas do Cerrado. Nas florestas semidecíduas altimontanas e montanas de relevo muito declivoso foi comum a ocorrência de muitos dos gêneros citados por Webster (1985) como típicos de florestas de altitudes, como Drymis, Podocarpus, Clethra, Ilex, Myrsine e Roupala, o que evidencia o laço florístico entre as duas fisionomias. Além do mais, a grande diversidade de Lauraceae, Rubiaceae e Melastomataceae registrada na área estudada demonstra laços florísticos com as florestas ombrófilas e semidecíduas altimontanas presentes no domínio da Mata Atlântica (Veloso et al. 1991). Cabe ressaltar, ainda, que as florestas ombrófilas interioranas do Estado de São Paulo se assemelharam com as florestas semidecíduas altimontanas e montanas de relevo declivoso de Minas Gerais presentes no domínio da Mata Atlântica e no contato com o Cerrado. Este fato sugere que a floresta estudada no Vale dos Cristais seja considerada como uma floresta semidecídua do domínio da Mata Atlântica, embora a mesma se encontre em uma zona de contato com o Cerrado.

As florestas semidecíduas do Estado de São Paulo, que ocupam regiões interioranas de clima estacional, foram as que apresentaram um padrão diferenciado, sendo mais similares com as florestas semidecíduas do domínio da Mata Atlântica do que aquelas presentes nos Cerrados do Distrito Federal, Goiás e Minas Gerais. Isso se deve ao fato das florestas paulistanas presentes no Cerrado não ocorrerem na área core desse domínio, e sim nos seus limites mais externos, o que também poderia estar contribuindo para que essas fitofisionomias se assemelhassem mais com a floresta atlântica senso lato. Além do mais, elas apresentam um clima do tipo $\mathrm{Cw}$ de Köppen, subtropical com inverno seco, exceto as áreas Pfa e Rcl (tabela 1), que difere do tipo Aw de Köppen, tropical de inverno seco, que é o clima mais comum nas áreas de florestas semidecíduas analisadas no domínio do Cerrado. Neste caso, o clima mais ameno contribuiu para que as florestas semidecíduas paulistanas consideradas no presente estudo fossem enquadradas como extensão do domínio da Mata Atlântica. De qualquer forma, o presente trabalho demonstra que as florestas semidecíduas paulistanas se separam das florestas ombrófilas presentes no mesmo Estado, fato também observado por Torres et al. (1997). De acordo com esses autores, as florestas paulistanas podem ser 
divididas em dois grupos, sendo um higrófilo, com precipitação anual média maior que $2.000 \mathrm{~mm}$ e sem estação seca, e outro mesófilo, cuja precipitação anual média está ao redor de $1.400 \mathrm{~mm}$ e a estação seca é variável.

Os resultados encontrados no presente trabalho reforçam a idéia de que as florestas semidecíduas do domínio da Mata Atlântica devem ser consideradas como extensão interiorana das florestas ombrófilas, como sugerido por Oliveira-Filho \& Fontes (2000). No caso das florestas semidecíduas presentes na zona de contato entre os domínios Mata Atlântica e Cerrado, a distinção entre as mesmas se deve, basicamente, à conformação do terreno e altitude. A floresta estudada (Vcr), presente nessa zona de contato, pode ser considerada como extensão do domínio da Mata Atlântica em função da sua maior similaridade com as florestas semidecíduas do mesmo domínio e com as florestas ombrófilas do interior de São Paulo. A área Vcr possui o registro de espécies típicas de áreas florestais altimontana e se encontra em terreno muito declivoso com a floresta localizando-se no fundo de um vale estreito e úmido, contribuindo para que espécies típicas da floresta ombrófila atlântica a alcancem via florestas ripárias que estão presentes nas calhas dos rios (Oliveira-Filho \& Ratter 2000). O forte vetor de ocupação que ocorre na porção sul da Região Metropolitana de Belo Horizonte, que inclui a bacia do Ribeirão Cristais, intensifica a pressão a que estão submetidos os remanescentes florestais presentes na região. Assim, qualquer forma de intervenção ou utilização racional na floresta semidecídua estudada deve ser vista com muitas ressalvas, dada a alta riqueza encontrada. Além do mais, deve ser considerado que atualmente as florestas presentes no domínio da Mata Atlântica em Minas Gerais apresentam, ainda, uso restrito por lei (Portaria No 055, de 14 de abril de 2004, do Instituto Estadual de Florestas - IEF). Por todas essas razões levantadas, aconselha-se que a floresta semidecídua que ocorre no Vale dos Cristais seja preservada, contribuindo, assim, para a conservação da biodiversidade do domínio Mata Atlântica na Região Metropolitana de Belo Horizonte.

Agradecimentos - À Construtora Norberto Odebrecht S.A. e à Sete Soluções e Tecnologia Ambiental Ltda., pelo financiamento em todas as etapas do trabalho; à Aline, pela ajuda na coleta de dados; ao especialistas, pela identificação de material: João R. Stehmann (Solanaceae), Júlio A. Lombardi (Celastraceae e Hippocrateaceae) e Marcos Sobral (Myrtaceae); ao CNPq, pela concessão da bolsa em parte do Doutoramento do primeiro autor.

\section{Referências bibliográficas}

APG II. 2003. An update of the Angiosperm Phylogeny Group classification for the orders and families of flowering plants; APG II. Botanical Journal of Linnean Society 141:399-436.

BERTANI, D.F, RODRIGUES, R.R., BATISTA, J.L.F \& SHEPHERD, G.J. 2001. Análise temporal da heterogeneidade florística e estrutural em uma floresta ribeirinha. Revista Brasileira de Botânica 24:11-23.

BORÉM, R.A.T. \& OLIVEIRA-FILHO, A.T. 2002. Fitossociologia do estrato arbóreo em uma toposseqüência alterada de mata atlântica, no município de Silva Jardim-RJ, Brasil. Revista Árvore 26: 727-742.

BOTREL, R.T., OLIVEIRA FILHO, A.T., RODRIGUES, L.A. \& CURI, N. 2002. Influência do solo e topografia sobre as variações da composição florística e estrutura da comunidade arbóreo-arbustiva de uma floresta estacional semidecidual em Ingaí, MG. Revista Brasileira de Botânica 25:195-213.

BRANDÃO, M. 1992. Caracterização geomorfológica, climática, florística e faunística da Serra do Curral em Belo Horizonte, MG. Daphne 2:13-38.

BRANDÃO, M., BRANDÃO, H. \& LACA-BUENDIA, J.P. 1998. A mata ciliar do rio Sapucaí, município de Santa Rita do Sapucaí-MG: fitossociologia. Daphne 8:36-48.

CARVALHO, L.M.T, FONTES, M.A.L. \& OLIVEIRAFILHO, A.T. 2000. Tree species distribution in canopy gaps and mature forest in an area of cloud forest of the Ibitipoca Range, south-eastern Brazil. Plant Ecology 149:9-22.

CETEC - FUNDAÇÃO CENTRO TECNOLÓGICO DE MINAS GERAIS. 1983. Diagnóstico ambiental do Estado de Minas Gerais. Cetec, Belo Horizonte.

DARGIE, T.C.D. 1984. On the integrated interpretation of indirect site ordinations: a case study using semiarid vegetation in southeastern Spain. Vegetatio 55:37-55.

FERRAZ, E.M.N., ARAÚJO, E.L. \& SILVA, S.I. 2004. Floristic similarities between lowland and montane áreas of Atlantic Coastal Forest in Northeastern Brazil. Plant Ecology 174:59-70.

FRANÇA, G.S. \& STEHMANN, J.R. 2004. Composição florística e estrutura do componente arbóreo de uma floresta altimontana no município de Camanducaia, Minas Gerais, Brasil. Revista Brasileira de Botânica 27:19-30.

GIULIETTI, A.M. \& PIRANI, J.R. 1988. Patterns of geographic distribution of some plant species from the Espinhaço Range, Minas Gerais and Bahia, Brazil. In Proceedings of a workshop on Neotropical distribution patterns (P.E. Vanzolini \& W.R. Heyer, eds.). Academia Brasileira de Ciências, Rio de Janeiro, p.39-69. 
IBGE - INSTITUTO BRASILEIRO DE GEOGRAFIA E ESTATÍSTICA. 2004. Mapa de Biomas do Brasil. Diretoria de Geociências, Rio de Janeiro.

IVANAUSKAS, N.M., RODRIGUES. R.R. \& NAVE, A.G. 1999. Fitossociologia de um trecho de Floresta Estacional Semidecidual em Itatinga, São Paulo, Brasil. Scientia Forestalis 56:83-99.

IVANAUSKAS, N.M., MONTEIRO, R. \& RODRIGUES, R.R. 2000. Similaridade florística entre áreas de Floresta Atlântica no Estado de São Paulo. Brazilian Journal of Ecology 1:71-81.

KAMINO, L.H.Y. 2002. Estação Ecológica da Universidade Federal de Minas Gerais: flora vascular e estudo comparativo de sua estrutura arbórea com as de outros fragmentos florestais da APA-Sul, MG. Dissertação de mestrado, Universidade Federal de Minas Gerais, Belo Horizonte.

KÖPPEN, W.P. 1948. Climatologia. Fundo de Cultura Economica, Mexico.

KREBS, C.J. 1989. Ecological methodology. Harper \& Row, New York.

KURTZ, B.C. \& ARAÚJO, D.S.D. 2000. Composição florística e estrutura do componente arbóreo de um trecho de Mata Atlântica na Estação Ecológica Estadual do Paraíso, Cachoeiras de Macucu, Rio de Janeiro, Brasil. Rodriguésia 51:69-112.

LEITÃO-FILHO, H.F. 1982. Aspectos taxonômicos das florestas do Estado de São Paulo. Silvicultura em São Paulo 16:197-206.

LEITÃO-FILHO, H.F. 1993. Ecologia da Mata Atlântica em Cubatão. Editora Unesp/Unicamp, São Paulo.

LOPES, W.P., SILVA, A.F., SOUZA, A.L. \& MEIRA-NETO, J.A.A. 2002. Estrutura fitossociológica de um trecho de vegetação arbórea no Parque Estadual do Rio Doce-Minas Gerais, Brasil. Acta Botanica Brasilica 16:443-456.

MCCUNE, B. \& GRACE, J.B. 2002. Analysis ecological communities. MjM Software Design, Glaneden Beach.

MCCUNE, B. \& MEFFORD, M.J. 1999. PC-ORD version 4.0: Multivariate analysis of ecological data; Users guide. MjM Software Design, Glaneden Beach.

MEGURO, M., PIRANI, J.R., MELLO-SILVA, R. \& GIULIETTI, A.M. 1996. Caracterização florística e estrutural de matas ripárias e capões de altitude da Serra do Cipó, Minas Gerais. Boletim de Botânica da Universidade de São Paulo 15:13-29.

MÉIO, B.B., FREITAS, C.V., JATOBÁ, L., SILVA, M.E.F., RIBEIRO, J.F. \& HENRIQUES, R.P.B. 2003. Influência da flora das florestas Amazônica e Atlântica na vegetação do cerrado sensu stricto. Revista Brasileira de Botânica 26:437-444.

MEYER, S.T., SILVA, A.F., MARCO-JÚNIOR, P. \& MEIRA-NETO, J.A.A. 2004. Composição florística da vegetação arbórea de um trecho de floresta de galeria do Parque Estadual do Rola-Moça na Região Metropolitana de Belo Horizonte, MG, Brasil. Acta Botanica Brasilica 18:701-709.
MORENO, M.R, NASCIMENTO, M.T. \& KURTZ, B.C. 2003. Estrutura e composição florística do estrato arbóreo em duas zonas altitudinais na mata atlântica de encosta da região do Imbé, RJ. Acta Botanica Brasilica 17:371-386.

OLIVEIRA, R.J., MANTOVANI, W. \& MELO, M.M.R.F. 2001. Estrutura do componente arbustivo-arbóreo da floresta atlântica de encosta, Peruíbe, SP. Acta Botanica Brasilica 15:391-412

OLIVEIRA-FILHO, A.T. 2008. TreeAtlan: Flora arbórea da Mata Atlântica e domínios adjacentes: um banco de dados envolvendo geografia, diversidade e conservação. Disponível em http://www.treeatlan.dcf.ufla.br (acesso em 04/2008).

OLIVEIRA-FILHO, A.T. \& FONTES, M.A.L. 2000. Patterns of floristic differentiation among Atlantic Forest in southeastern Brazil, and the influence of climate. Biotropica 32:793-810.

OLIVEIRA-FILHO, A.T. \& MACHADO, J.N.M. 1993. Composição florística de uma floresta semidecídua montana, na Serra de São José, Tiradentes, Minas Gerais. Acta Botanica Brasilica 7:71-88.

OLIVEIRA-FILHO, A.T. \& RATTER, J.A. 1995. A study of the origin of Central Brazilian forests by the analysis of plant species distribution patterns. Edinburgh Journal of Botany 52:141-194.

OLIVEIRA-FILHO, A.T. \& RATTER, J.A. 2000. Padrões florísticos das matas ciliares da região dos cerrados e a evolução das paisagens do Brasil Central durante Quaternário tardio. In Matas Ciliares: conservação e recuperação (R.R. Rodrigues \& H.F. Leitão-Filho, eds.). EDUSP, São Paulo, p.73-89.

OLIVEIRA-FILHO, A.T., VILELA, E.A., GAVILANES, M.L. \& CARVALHO, D.A. 1994. Comparison of the woody flora and soils of six areas of montane semideciduous forest in southern Minas Gerais, Brazil. Edinburgh Journal of Botany 51:355-389.

OLIVEIRA-FILHO, A.T., CARVALHO, D.A., FONTES, M.A.L., VAN DEN BERG, E., CURI, N. \& CARVALHO, W.A.C. 2004. Variações estruturais do compartimento arbóreo de uma floresta semidecídua alto-montana na chapada das Perdizes, Carrancas, MG. Revista Brasileira de Botânica 27:291-309.

OLIVEIRA-FILHO, A.T., JARENKOW. J.A. \& RODAL, M.J.N. 2006. Floristic relationships of seasonally dry forests of eastern South America based on tree species distribution patterns. In Neotropical savannas and dry forests: plant diversity, biogeography and conservation (R.T. Pennington, J.A. Ratter \& G.P. Lewis, eds.). CRC Press - Taylor and Francis Group, Boca Raton, p.159-192.

PEDRALLI, G., TEIXEIRA, M.C.B, FREITAS, V.L.O., MEYER, S.T. \& NUNES, Y.R.F. 2000. Florística e fitossociologia da Estação Ecológica do Tripuí, Ouro Preto, MG. Ciências Agrotécnicas 24:103-136. 
PEIXOTO, A.L. \& GENTRY, A. 1990. Diversidade e composição florística da mata de tabuleiro na Reserva Florestal de Linhares (Espírito Santo, Brasil). Revista Brasileira de Botânica 13:19-25.

PEIXOTO, G.L, MARTINS, S.V, SILVA, A.F. \& SILVA, E. 2004. Composição florística do componente arbóreo de um trecho de Floresta Atlântica na Área de Proteção Ambiental da Serra da Capoeira Grande, Rio de Janeiro, RJ, Brasil. Acta Botanica Brasilica 18:151-160.

RATTER, J.A., BRIDGEWATER, S. \& RIBEIRO, J.F. 2003. Analysis of the floristic composition of the Brazilian Cerrado vegetation III: comparison of the woody vegetation of 376 areas. Edinburgh Journal of Botany 60:57-109.

RODRIGUES, L.A., CARVALHO, D.A., OLIVEIRAFILHO, A.T., BOTREL, R.T. \& SILVA, E.A. 2003. Florística e estrutura da comunidade arbórea de um fragmento florestal em Luminárias, MG. Acta Botanica Brasilica 17:71-87.

SALIS, S.M., SHEPHERD, G.J. \& JOLY, C.A. 1995. Floristic comparison of mesophytic semideciduous forests of the interior of the state of São Paulo, southeast Brazil. Vegetatio 119:155-164.

SCUDELLER, V.V., MARTINS, F.R. \& SHEPHERD, G.J. 2001. Distribution and abundance of arboreal species in the atlantic ombrophilous dense forest in Southeastern Brazil. Plant Ecology 152:185-199

SILVA, A.F. 2000. Floresta Atlântica. In Lista vermelha das espécies ameaçadas de extinção da flora de Minas Gerais (M.P. Mendonça \& L.V. Lins, eds.). Fundação Biodiversitas/Fundação Zoobotânica de Belo Horizonte, Belo Horizonte, p.45-53.

SILVA, G.C. \& NASCIMENTO, M.T. 2001. Fitossociologia de um remanescente de mata sobre tabuleiros no norte do Estado do Rio de Janeiro (Mata do Carvão). Revista Brasileira de Botânica 24:51-62.

SILVA, L.A. \& SOARES, J.J. 2002. Levantamento fitossociológico em um fragmento de floresta estacional semidecídua, no município de São Carlos, SP. Acta Botanica Brasilica 16:205-216.
SILVA, N.R.S., MARTINS, S.V., MEIRA-NETO, J.A.A. \& SOUZA, A.L. 2004. Composição florística e estrutura de uma floresta estacional semidecidual montana em Viçosa, MG. Revista Árvore 28:397-405.

SILVA, V.F, VENTURIN, N., OLIVEIRA-FILHO, A.T., MACEDO, R.L.G., CARVALHO, W.A.C. \& VAN DEN BERG, E. 2003. Caracterização estrutural de um fragmento de floresta semidecídua no município de Ibituruna, MG. Cerne 9:95-110.

SILVA-JÚNIOR, M.C. 2004. Fitossociologia e estrutura diamétrica da mata de galeria do Taquara, na Reserva Ecológica do IBGE, DF. Revista Árvore 28:419-428.

TER BRAAK, C.J.F. 1995. Ordination. In Data analysis in community and landscape ecology (R.H.G. Jongman, C.J.F. ter Braak \& O.F.R. van Tongeren, eds.). Cambridge University Press, Cambrigde, p.91-173.

TORRES, R.B., MARTINS, F.R. \& KINOSHITA, L.S. 1997. Climate, soils and tree flora relationship in forests in the state of São Paulo, southeastern Brazil. Revista Brasileira de Botânica 20:41-49.

VAN DEN BERG, E. \& OLIVEIRA-FILHO, A.T. 2000. Composição florística e estrutura fitossociológica de uma floresta ripária em Itutinga, $\mathrm{MG}$, e comparação com outras áreas. Revista Brasileira de Botânica 23:231253.

VELOSO, H.P., RANGEL-FILHO, A.L.R. \& LIMA, J.C.A. 1991. Classificação da vegetação brasileira adaptada a um sistema universal. Instituto Brasileiro de Geografia e Estatística, Rio de Janeiro.

WEBSTER, G.L. 1995. The panorama of Neotropical Cloud Forests. In Biodiversity and conservation of Neotropical Montane Forests (S.P. Churchill, H. Balslev, E. Forero \& J.L. Luteyn, eds.). The New York Botanical Garden, New York, p.53-77.

WERNECK, M.S, PEDRALLI, G., KOENIG, R. \& GISEKE, L.F. 2000. Florística e estrutura de três trechos de uma floresta semidecídua na Estação Ecológica do Tripuí, Ouro Preto, MG. Revista Brasileira de Botânica 23:97106. 
